\title{
High gamma-glutamyl hydrolase and low folylpolyglutamate synthetase expression as prognostic biomarkers in patients with locally advanced gastric cancer who were administrated postoperative adjuvant chemotherapy with S-1
}

\author{
Yukio Maezawa ${ }^{1,5} \cdot$ Kentaro Sakamaki $^{2} \cdot$ Naohide Oue $^{3}$ - Yayoi Kimura ${ }^{4} \cdot$ Itaru Hashimoto $^{1,5} \cdot$ Kentaro Hara $^{1,5}$. \\ Kazuki Kano ${ }^{1}$. Toru Aoyama ${ }^{5}$. Yukihiko Hiroshima ${ }^{1} \cdot$ Takanobu Yamada $^{1}$. Naoto Yamamoto ${ }^{1} \cdot$ Takashi Ogata $^{1}$. \\ Hiroyuki Ito $^{6} \cdot$ Haruhiko Cho $^{5,7}$. Manabu Shiozawa' ${ }^{1}$. Takaki Yoshikawa ${ }^{5,8}$. Soichiro Morinaga ${ }^{1}$ - Yasushi Rino ${ }^{5}$. \\ Wataru Yasui ${ }^{3} \cdot$ Munetaka Masuda $^{5} \cdot$ Yohei Miyagi $^{9} \cdot$ Takashi Oshima $^{1}$ (i)
}

Received: 14 September 2019 / Accepted: 15 November 2019 / Published online: 21 November 2019

(c) The Author(s) 2019

\begin{abstract}
Purpose The enzymes gamma-glutamyl hydrolase (GGH) and folylpolyglutamate synthetase (FPGS) regulate intracellular folate concentrations needed for cell proliferation, DNA synthesis, and repair. High GGH expression affects 5-FU thymidylate synthase (TS) inhibition and is a risk factor for various malignancies. Here, the clinical significance of $G G H$ and $F P G S$ expression was investigated in Stage II/III gastric cancer patients undergoing postoperative adjuvant chemotherapy with S-1. Methods Surgical specimens of cancer tissue and adjacent normal mucosa, obtained from 253 patients with previously untreated gastric cancer, were examined. GGH and FPGS mRNA expression was measured by qPCR to evaluate their clinicopathological significance in gastric cancer patients after curative resection.

Results While FPGS expression showed no significant differences between the cancerous and normal samples, $G G H$ expression was higher in cancer tissue than in adjacent normal mucosa. High $G G H$ expression was correlated with age, histological type, and vascular invasion. Overall survival (OS) of patients with high $G G H$ mRNA expression was significantly poorer than of patients with low GGH expression. Multivariate analysis showed that high GGH expression was an independent prognostic factor of OS (HR: 2.58, 95\% CI 1.29-5.16). Patients who received S-1 adjuvant treatment showed a significantly poor OS between high GGH/low FPGS and low GGH/high FPGS. Patients without adjuvant treatment showed no significant difference.

Conclusion $G G H$ expression was significantly higher in gastric cancer tissue than in adjacent normal mucosa. High $G G H$ and low FPGS expression is a useful independent predictor of poor outcomes in stage II/III gastric cancer patients undergoing postoperative adjuvant chemotherapy with S- 1 .
\end{abstract}

Keywords Gastric cancer · Gamma-glutamyl hydrolase (GGH) · Folylpolyglutamate synthetase (FPGS) · S-1 · Prognostic factor

\section{Introduction}

Gastric cancer was the fifth most common in new cases of cancer $(1,033,701$ cases $)$ and the third most common in cancer-related deaths (781,631 deaths) in 2018 (Bray et al. 2018). Curative resection and postoperative adjuvant

Takashi Oshima

oshimat@kcch.jp

Extended author information available on the last page of the article chemotherapy is the standard treatment for locally advanced gastric cancer in Japan. Since Adjuvant Chemotherapy Trial of S-1 for Gastric Cancer (ACTS-GC), adjuvant chemotherapy with $\mathrm{S}-1$ is one of the standard treatments for pathological TNM stage II/III gastric cancer (except pT1N2-3/ pT3N0) for the prevention of recurrence (Sakuramoto et al. 2007; Japanese gastric cancer treatment guidelines 2014 (ver. 4) 2017). Moreover, CLASSIC and JACCRO-07 trials have been used to confirm the effectiveness of capecitabine plus oxaliplatin (CapeOX) therapy and S-1 plus docetaxel 
(DS) therapy; fluoropyrimidine is still the key drug used in the postoperative adjuvant chemotherapy for gastric cancer (Sakuramoto et al. 2007; Bang et al. 2012; Noh et al. 2014). However, the outcomes of treatment are still insufficient, as recurrence occurs in $20-60 \%$ of patients, even after a complete resection and the administration of the appropriate adjuvant therapy (Maehara et al. 2000; Rivera et al. 2007). The personalization of postoperative adjuvant chemotherapy treatment using biomarkers is a promising strategy to improve the survival of patients with localized advanced gastric cancer. However, a specific biomarker for use in predicting the therapeutic effects of fluorinated pyrimidine and the long-term outcomes of patients with locally advanced gastric cancer has yet to be identified (Pizzorno et al. 1988; Shubbar et al. 2013; Melling et al. 2017).

Folic acid is a molecule which is necessary for cell proliferation, DNA synthesis, and repair. Gamma-glutamyl hydrolase (GGH) and folylpolyglutamate synthetase (FPGS) are enzymes which regulate intracellular folate concentrations (Bailey 2010). GGH promotes the production of monoglutamyl acid folate, a metabolite of folic acid required for DNA synthesis. On the other hand, FPGS catalyzes the hydrolysis of monoglutamate folate into polyglutamate, which has a high intracellular retention (Bailey 2010). Thus, GGH and FPGS strongly influence DNA synthesis in cancer cells.

Previous studies have reported that high GGH expression is a risk factor for the prognosis of various malignancies (Shubbar et al. 2013; Melling et al. 2017). Moreover, the expression of GGH and FPGS was reported to affect thymidylate synthase (TS) inhibition of 5-fluorouracil (5-FU) in a range of malignancies (Cheradame et al. 1997; Sakamoto et al. 2008; Kim et al. 2013). Recently, it was reported that high GGH expression is a risk factor of lymph node recurrence after surgery in patients with stage II/III gastric cancer, using clinical specimens of ACTS-GC (Terashima et al. 2017). However, the relationship between the expression of GGH and FPGS and the effect of S- 1 in adjuvant chemotherapy has not yet been evaluated. In this study, we examined the clinical significance of GGH and FPGS expression in patients with stage II/III gastric cancer who were undertaking postoperative adjuvant chemotherapy with S-1.

\section{Materials and methods}

\section{Patients and samples}

We studied surgical specimens of cancer tissue and adjacent normal mucosa obtained from 253 patients with gastric cancer undergoing gastrectomy as the first treatment. The patients underwent surgery at the Department of Surgery (Yokohama City University), the Gastroenterological Center (Yokohama City Medical Center), and the Department of
Gastrointestinal surgery (Kanagawa Cancer Center) between March 2002 and July 2012. Informed consent was obtained from each patient, with all protocols approved by the ethics committees of each institute before the initiation of the study. All tissue samples were embedded in O.C.T. compound (Sakura Finetechnical Co., Ltd., Tokyo) and immediately stored at $-80^{\circ} \mathrm{C}$ until further use. None of the patients had any other malignancies. The specimens were stained with hematoxylin and eosin and examined histopathologically. Sections consisting of $>80 \%$ cancer cells were used to prepare total RNA.

\section{Quantitative reverse-transcriptase polymerase chain reaction (qRT-PCR)}

qRT-PCR was performed with iQ SYBR Green Supermix (Bio-Rad Laboratories). PCR was carried out in a total volume of $15 \mu \mathrm{l}$, which included $0.2 \mu \mathrm{g}$ of cDNA derived from $75 \mathrm{ng}$ of RNA, $0.4 \mu \mathrm{M}$ of each primer, $7.5 \mu \mathrm{l}$ of iQ SYBR Green Supermix containing dATP, dCTP, dGTP, and dTTP at concentrations of $400 \mu \mathrm{M}$ each, as well as 50 units $/ \mathrm{ml}$ of iTag DNA polymerase. The PCR cycles consisted of $3 \mathrm{~min}$ at $95^{\circ} \mathrm{C}$, followed by 40 cycles of denaturation of the cDNA for $10 \mathrm{~s}$ at $95^{\circ} \mathrm{C}$, annealing for $10 \mathrm{~s}$, a primer extension for $20 \mathrm{~s}$ at $72{ }^{\circ} \mathrm{C}$, followed by $10 \mathrm{~min}$ at $72{ }^{\circ} \mathrm{C}$. The annealing temperature was set at $57^{\circ} \mathrm{C}$ and $59^{\circ} \mathrm{C}$ for GGH and FPGS, respectively. To distinguish specific from nonspecific products and primer dimmers, melting curve analyses were performed. To evaluate the specific mRNA expression in the samples, a standard curve was produced for each run, measuring three points of the human control cDNA (Clontech Laboratories, Inc., CA, USA). The concentration of each sample was calculated by relating its crossing point to a standard curve. The measurement was performed three times and the average value was adopted. The PCR primer sequences of GGH, FPGS and $\beta$-actin, used as an internal control, are shown in Table 1.

\section{Statistical analysis}

Gene expression levels were compared between gastric cancer and adjacent normal mucosa by the Wilcoxon test. The expression levels of GGH and FPGS mRNA were categorized as low or high based on a cut-off value calculated using to the maximum Chi-square $\left(\chi^{2}\right)$ test. The relationship between mRNA expression and potential explanatory variables, including age, gender, tumor size, depth of invasion, lymph-node metastasis, distant metastasis, stage, lymphatic invasion, venous invasion, and histological type, were evaluated with the $\chi^{2}$ test. The associations between the expression of $G G H$ and FPGS mRNA and survival were assessed using the Kaplan-Meier method, then compared using the log-rank test. A Cox proportional-hazards 
Table 1 PCR primers and conditions

\begin{tabular}{|c|c|c|c|}
\hline Gene & Primer & $\begin{array}{l}\text { Annealing tempera- } \\
\text { ture }\left({ }^{\circ} \mathrm{C}\right)\end{array}$ & $\begin{array}{l}\text { Product } \\
\text { size } \\
\text { (bp) }\end{array}$ \\
\hline \multicolumn{4}{|l|}{$G G H$} \\
\hline Sense & 5'-AGTTGCGTTACACCCTTTCTTGAC-3' & 57 & 151 \\
\hline Antisense & 5'-GCTCGCTCCAACCGACTGC-3' & & \\
\hline \multicolumn{4}{|l|}{ FPGS } \\
\hline Sense & 5'-TTCCGCTTCCTGACACTC-3' & 59 & 116 \\
\hline Antisense & 5'-GGCTTCCTGATGATGTTGG-3' & & \\
\hline \multicolumn{4}{|l|}{$\beta$-Actin } \\
\hline Sense & 5'-AGTTGCGTTACACCCTTTCTTGAC-3' & 60 & 171 \\
\hline Antisense & 5'-GCTCGCTCCAACCGACTGC-3' & & \\
\hline
\end{tabular}

model was used to perform univariate analyses and stepwise multivariate analyses to determine the risk factors. The software program SPSS (ver. 23.0; IBM Corp., Armonk, NY, USA) was used to perform all the statistical analyses. Two-sided $P$ values were calculated, and $P<0.05$ was defined as a statistically significant difference. Data were expressed as medians (range).

\section{Results}

\section{GGH and FPGS mRNA expression in gastric cancer tissue and adjacent normal mucosa}

The $G G H$ mRNA expression levels were higher in cancer tissue (0.478 [0.000-52.951]) than in adjacent normal mucosa $(0.000$ [0.000-6.597] $P<0.001)$. On the other hand, there was no significant difference in the FPGS mRNA expression level between cancer tissue $(3.458$ [0.000-63.019]) and adjacent normal mucosa (3.295 [0.000-80.960] $P=0.67$ ) (Fig. 1a, b).

\section{Relationship of GGH and FPGS mRNA expression levels to clinicopathological features}

The expression levels of the GGH and FPGS genes were categorized as low or high based on a cut-off value calculated using the maximum Chi-square test. The relationship of the expression level of $G G H$ mRNA or FPGS mRNA to the clinicopathological features was then examined. The expression level of $G G H$ mRNA was related to age, histological type, and vascular invasion. On the other hand, the expression level of FPGS mRNA was related to vascular invasion and lymphatic invasion (Table 2).

\section{Uni- and multivariate analysis of the relationship of clinicopathological factors and GGH/FPGS gene expression levels to overall survival}

Univariate Cox regression analyses found that high levels of $G G H$ mRNA expression, pathological stage, and lymphatic invasion were the significant prognostic factors. On the other hand, according to multivariate Cox regression analysis, high levels of $G G H$ mRNA expression, pathological stage, lymphatic invasion, and no postoperative adjuvant treatment with $\mathrm{S}-1$ were the independent prognostic factors. The expression of FPGS mRNA was not selected as a significant prognostic factor (Table 3 ).

\section{Comparison of overall survival rates by expression levels of GGH or FPGS mRNA in gastric cancer tissue}

The median follow-up time was 1823 days. During this follow-up period, 127 patients died. The 5-year overall survival rate (OS) in patients with low and high levels of GGH mRNA expression were $76.8 \%$ and $61.8 \%$, respectively $(P=0.017$, Fig. 2a). The 5-year OS rate in patients with low and high levels of FPGS mRNA expression were $59.9 \%$ and $65.0 \%$, respectively ( $P=0.425$, Fig. 2 b).

Stratified by whether S-1 adjuvant treatment was performed or not, the OS in patients who received $S-1$ adjuvant treatment was significantly poorer in patients with high levels of $G G H$ mRNA expression than those with low levels of $G G H$ mRNA expression $(P=0.043$, Fig. 3a). On the other hand, in patients who underwent surgery alone, there was no significant difference in the OS between patients with high and low level of $G G H$ mRNA expression ( $P=0.21$, Fig. $3 \mathrm{~b})$.

The 5-year OS in patients with various combinations of GGH/FPGS expression, that is, low/low, low/high, high/high, and high/low, was $88.9 \%, 73.6 \%, 63.5 \%$, and $47.8 \%$, respectively $(P=0.019$, Fig. 4$)$. Stratified by 
Fig. 1 a Comparison of expression levels of the GGH gene between gastric cancer tissue and adjacent normal mucosa $(P<0.001)$. b Comparison of expression levels of the FPGS gene between gastric cancer tissue and adjacent normal mucosa $(P=0.82)$ a

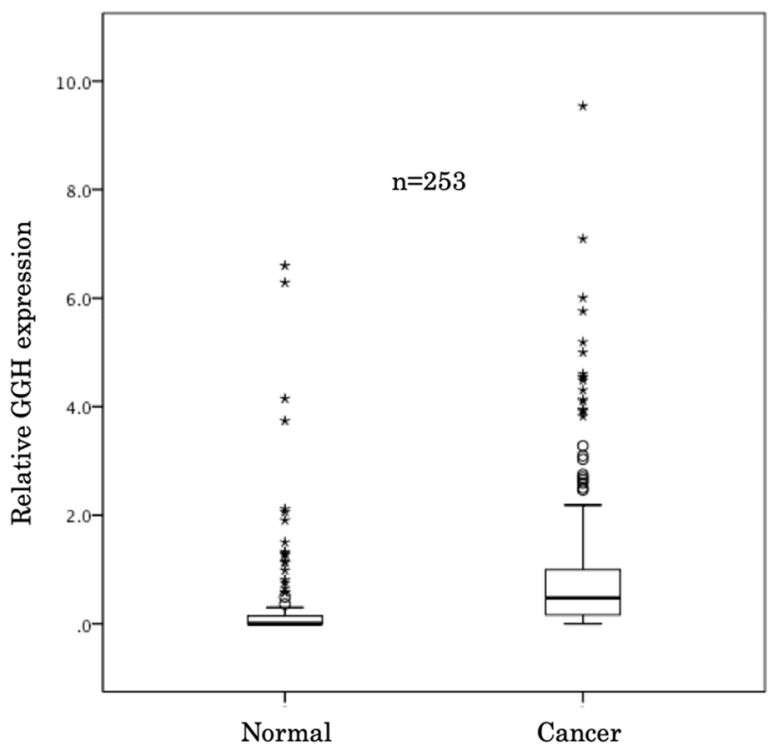

\begin{tabular}{|c|c|c|c|}
\hline & normal & tumor & P value \\
\hline $\begin{array}{c}\text { GGH expression, median } \\
\text { (range) }\end{array}$ & 0.000 & 0.478 & $<0.001$ \\
\hline
\end{tabular}

b

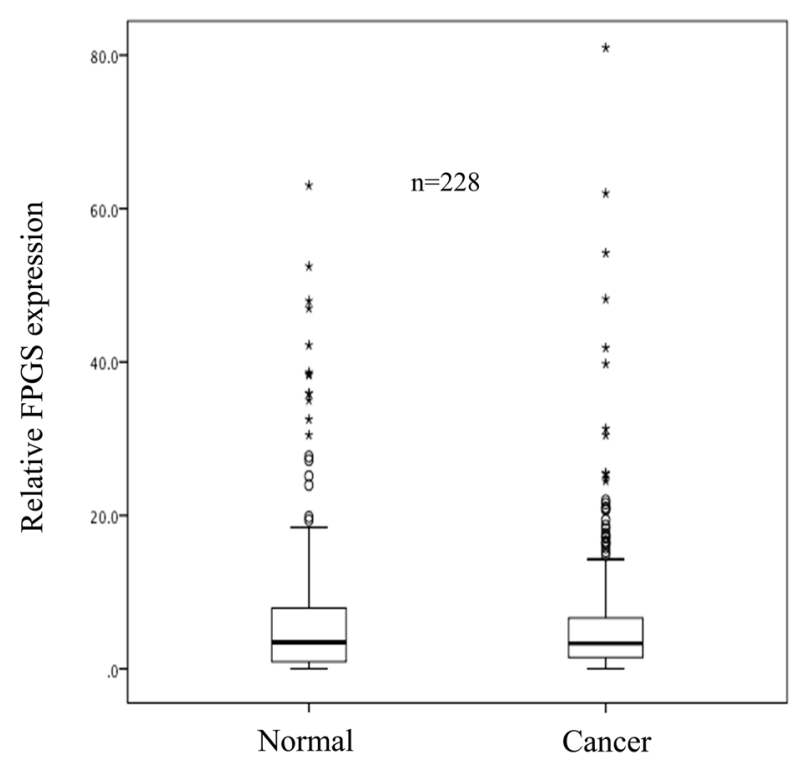

\begin{tabular}{|c|c|c|c|}
\hline & normal & tumor & P value \\
\hline $\begin{array}{c}\text { FPGS expression, median } \\
\text { (range) }\end{array}$ & $\begin{array}{c}3.458 \\
(0.000-63.019)\end{array}$ & $\begin{array}{c}3.295 \\
(0.000-80.960)\end{array}$ & 0.82 \\
\hline
\end{tabular}

whether postoperative adjuvant treatment with S-1 was performed, the OS in patients who received S-1 adjuvant treatment was significantly poorer in patients with high levels of $G G H$ mRNA expression and low levels of FPGS mRNA expression than those with low levels of
$G G H$ mRNA expression and high levels of FPGS mRNA expression $(P=0.039$, Fig. 5a). On the other hand, there was no significant difference in patients who underwent surgery alone $(P=0.525$, Fig. $5 b)$. 
Table 2 Comparison of patient's background and pathological outcomes

\begin{tabular}{|c|c|c|c|c|c|c|c|}
\hline \multirow[t]{2}{*}{ Variables } & \multirow{2}{*}{$\begin{array}{l}\text { All Patients } \\
(n=253)\end{array}$} & \multicolumn{2}{|c|}{ GGH expression } & \multirow[t]{2}{*}{$P$ value } & \multicolumn{2}{|c|}{ FPGS expression } & \multirow[t]{2}{*}{$P$ value } \\
\hline & & $\begin{array}{l}\text { High group } \\
(n=211)\end{array}$ & $\begin{array}{l}\text { Low group } \\
(n=42)\end{array}$ & & $\begin{array}{l}\text { High group } \\
(n=222)\end{array}$ & $\begin{array}{l}\text { Low group } \\
(n=31)\end{array}$ & \\
\hline $\begin{array}{l}\text { Age (years), } \\
\text { median (range) }\end{array}$ & $65(38-98)$ & $70(48-98)$ & $64(38-87)$ & $<0.001$ & $68(44-89)$ & 69 (380-98) & 0.46 \\
\hline Gender & & & & 0.94 & & & 0.25 \\
\hline Male & $170(67.2 \%)$ & $142(67.3 \%)$ & $2866.7 \%)$ & & $152(68.5 \%)$ & $18(58.1 \%)$ & \\
\hline Female & $83(32.8 \%)$ & $69(32.7 \%)$ & $14(33.3 \%)$ & & $70(31.5 \%)$ & $1341.9 \%)$ & \\
\hline Histological type & & & & 0.012 & & & 0.66 \\
\hline Undifferentiated & $140(55.3 \%)$ & $108(51.2 \%)$ & $3276.2 \%)$ & & $124(55.9 \%)$ & $16(51.6 \%)$ & \\
\hline Differentiated & $112(44.3 \%)$ & $10248.3 \%)$ & $10(23.8 \%)$ & & $98(44.1 \%)$ & $15(48.4 \%)$ & \\
\hline Tumor size (mm) & & & & 0.12 & & & 0.84 \\
\hline$<65$ & $135(53.4 \%)$ & $108(51.2 \%)$ & $27(64.3 \%)$ & & $119(53.6 \%)$ & $16(51.6 \%)$ & \\
\hline $65 \leq$ & $118(46.6 \%)$ & $103(48.8 \%)$ & $15(35.7 \%)$ & & $103(46.4 \%)$ & $15(48.4 \%)$ & \\
\hline $\begin{array}{l}\text { Pathological } T \\
\text { factor }\end{array}$ & & & & 0.80 & & & 0.32 \\
\hline T1-3 & $119(47.0 \%)$ & $10047.4 \%)$ & $19(45.2 \%)$ & & $107(48.2 \%)$ & $12(38.7 \%)$ & \\
\hline $\mathrm{T} 4$ & $134(53.0 \%)$ & $111(52.6 \%)$ & $23(54.8 \%)$ & & $115(51.8 \%)$ & $19(61.3 \%)$ & \\
\hline $\begin{array}{l}\text { Pathological } N \\
\text { factor }\end{array}$ & & & & 0.60 & & & 0.69 \\
\hline No & $56(22.1 \%)$ & $48(22.75 \%)$ & $8(19.1 \%)$ & & $50(22.5 \%)$ & $6(19.4 \%)$ & \\
\hline $\mathrm{N} 1-3$ & $197(77.9 \%)$ & $163(77.3 \%)$ & $34(81.0 \%)$ & & $172(77.5 \%)$ & $25(80.6 \%)$ & \\
\hline Stage & & & & 0.71 & & & 0.59 \\
\hline II & $103(49.7 \%)$ & $87(41.2 \%)$ & $16(38.1 \%)$ & & $89(40.1 \%)$ & $14(45.2 \%)$ & \\
\hline III & $150(59.3 \%)$ & $124(58.8 \%)$ & $26(61.9 \%)$ & & $133(59.9 \%)$ & $17(54.8 \%)$ & \\
\hline Vascular invasion & & & & 0.028 & & & 0.086 \\
\hline v0 & $73(28.9 \%)$ & $55(26.1 \%)$ & $18(42.9 \%)$ & & $60(27.0 \%)$ & $13(41.9 \%)$ & \\
\hline v1-3 & $180(71.1 \%)$ & $156(73.9 \%)$ & $24(57.1 \%)$ & & $162(73.0 \%)$ & $18(58.1 \%)$ & \\
\hline Lymphatic invasion & & & & 0.87 & & & 0.094 \\
\hline ly0 & $81(32.0 \%)$ & $68(32.2 \%)$ & $13(31.0 \%)$ & & $67(30.2 \%)$ & $14(45.2 \%)$ & \\
\hline ly $1-3$ & $172(68.0 \%)$ & $143(67.8 \%)$ & $29(69.0 \%)$ & & $155(69.8 \%)$ & $17(54.8 \%)$ & \\
\hline Adjuvant therapy & & & & 0.35 & & & 0.46 \\
\hline Yes & $146(42.3 \%)$ & $119(56.4 \%)$ & $27(64.3 \%)$ & & $130(58.6 \%)$ & $16(51.6 \%)$ & \\
\hline No & $107(57.7 \%)$ & $92(43.6 \%)$ & $15(35.7 \%)$ & & $92(41.4 \%)$ & $15(48.4 \%)$ & \\
\hline
\end{tabular}

\section{Discussion}

In this study, we measured the levels of $G G H$ and $F P G S$ mRNA expression in cancer tissues and adjacent normal mucosa in patients with stage II/III gastric cancer. We then examined the relationship between the expression levels of these genes and the clinicopathological features and longterm outcomes to evaluate the clinical significance of $G G H$ and FPGS mRNA expression in gastric cancer tissue in patients with Stage II/III gastric cancer undergoing postoperative adjuvant chemotherapy with $\mathrm{S}-1$.

First, the expression levels of $G G H$ and FPGS mRNA in gastric cancer tissue and adjacent normal mucosa were compared. Several previous studies have compared the relative expression levels of $G G H$ and $F P G S$ mRNA between various types of cancer tissue and adjacent normal tissue
(Kidd et al. 2005; Pollard et al. 2009; Shubbar et al. 2013). These studies reported that $G G H$ mRNA expression was higher in cancer tissue compared to normal tissue in breast cancer (Shubbar et al. 2013) and bladder cancer (Pollard et al. 2009). Our results are consistent with these findings, as the expression levels of $G G H$ mRNA were found to be significantly higher in the gastric cancer tissue than in the paired adjacent normal mucosa. As for FPGS expression, it has been previously reported that the expression of FPGS was higher in cancer tissue than normal mucosa in colorectal cancer (Odin et al. 2003; Kidd et al. 2005). However, in our study, there was no significant difference in the expression levels of FPGS mRNA between the cancer tissue and adjacent normal tissue.

Next, the relationship between the expression levels of $G G H$ and FPGS mRNA and the clinicopathological features 
Table 3 Uni- and multivariate Cox proportional-hazards analysis of clinicopathological factors (overall survival)

\begin{tabular}{|c|c|c|c|c|c|c|c|}
\hline \multirow[t]{2}{*}{ Characteristics } & \multirow[t]{2}{*}{ Number } & \multicolumn{3}{|c|}{ Univariate } & \multicolumn{3}{|c|}{ Multivariate } \\
\hline & & HR & $95 \% \mathrm{CI}$ & $P$ value & HR & $95 \% \mathrm{CI}$ & $P$ value \\
\hline Expression of GGH & & & & 0.02 & & & 0.006 \\
\hline Low & 42 & 1.00 & & & 1.00 & & \\
\hline High & 211 & 2.27 & $1.14-4.51$ & & 2.65 & $1.32-5.31$ & \\
\hline Expression of FPGS & & & & 0.43 & & & \\
\hline Low & 42 & 1.00 & & & & & \\
\hline High & 211 & 1.27 & $0.71-2.28$ & & & & \\
\hline Age(years) & & & & 0.81 & & & \\
\hline$<65$ & 135 & 1.00 & & & & & \\
\hline $65 \leq$ & 118 & 1.05 & $0.69-1.62$ & & & & \\
\hline Gender & & & & 0.16 & & & \\
\hline Female & 83 & 1.00 & & & & & \\
\hline Male & 170 & 1.34 & $0.88-2.15$ & & & & \\
\hline Tumor size (mm) & & & & 0.84 & & & \\
\hline$<65$ & 135 & 1.00 & & & & & \\
\hline $65 \leq$ & 118 & 1.04 & $0.70-1.57$ & & & & \\
\hline Histological type & & & & 0.82 & & & \\
\hline Undifferentiated & 140 & 1.00 & & & & & \\
\hline Differentiated & 113 & 1.05 & $070-1.58$ & & & & \\
\hline Pathological Stage & & & & $<0.001$ & & & $<0.001$ \\
\hline II & 103 & 1.00 & & & 1.00 & & \\
\hline III & 150 & 2.33 & $1.47-3.71$ & & 2.44 & $1.50-3.95$ & \\
\hline Vascular invasion & & & & 0.28 & & & \\
\hline v0 & 73 & 1.00 & & & & & \\
\hline v1-3 & 180 & 1.29 & $0.81-2.03$ & & & & \\
\hline Lymphatic invasion & & & & 0.008 & & & 0.011 \\
\hline ly0 & 81 & 1.00 & & & 1.00 & & \\
\hline ly $1-3$ & 172 & 1.91 & $1.18-3.08$ & & 1.94 & $1.16-3.22$ & \\
\hline Adjuvant therapy & & & & 0.49 & & & 0.018 \\
\hline Yes & 146 & 1.00 & & & 1.00 & & \\
\hline No & 107 & 1.15 & $0.77-1.64$ & & 1.68 & $1.09-2.59$ & \\
\hline
\end{tabular}

in patients with stage II/III gastric cancer were examined. It was reported that GGH expression was significantly associated with a high histological tumor grade (BRE grade III, $P<0.001$ ), as well as ER/PR receptors in patients with breast cancer (Shubbar et al. 2013). As for FPGS, to the best of our knowledge, there are no reports. In this study, high levels of $G G H$ mRNA expression were significantly correlated with age, histological type, and vascular invasion. High levels of FPGS mRNA expression, on the other hand, were found to be related to vascular invasion and lymphatic invasion.

The relationship between the expression levels of $G G H$ and FPGS mRNA in cancer tissue and long-term outcomes in patients with stage II/III gastric cancer was then assessed. Several studies have previously reported that patients with high levels of $G G H$ mRNA expression in cancer tissue resulted in significantly poor outcomes compared to patients with low levels of $G G H$ mRNA expression. Melling et al.
(2017) reported that 10-year recurrence-free survival was significantly higher in patients with high levels of $G G H$ expression compared to patients with low level of $G G H$ expression in ERG negative prostate cancer $(P=0.0002)$. Shubber et al. (2013) reported that 8-year disease-specific survival (DSS) was significantly different between patients expressing GGH (39\%) and patients whose tumors were GGH-negative $(68 \%, P=0.037)$ in invasive breast cancer. In addition, univariate analysis showed that GGH expression exhibited a lower DSS probability, with a 2.7-fold increase in risk of death $(P=0.04)$ (Shubbar et al. 2013). As for FPGS, it was reported that 5-year tumor-specific survival (TSS) was significantly better in patients with high levels of FPGS mRNA expression (75\%) than patients with low levels of $F P G S$ mRNA expression (35\%, $P=0.002)$. In addition, FPGS expression has been previously reported to be an independent significant prognostic factor of TSS in patients with colorectal cancer (Odin et al. 2003). 
Fig. 2 a Comparison of overall survival between high and low expression levels of the GGH gene in gastric cancer tissue $(P=0.017)$. b Comparison of overall survival between high and low expression levels of the FPGS gene in gastric cancer tissue $(P=0.425)$

\section{a}

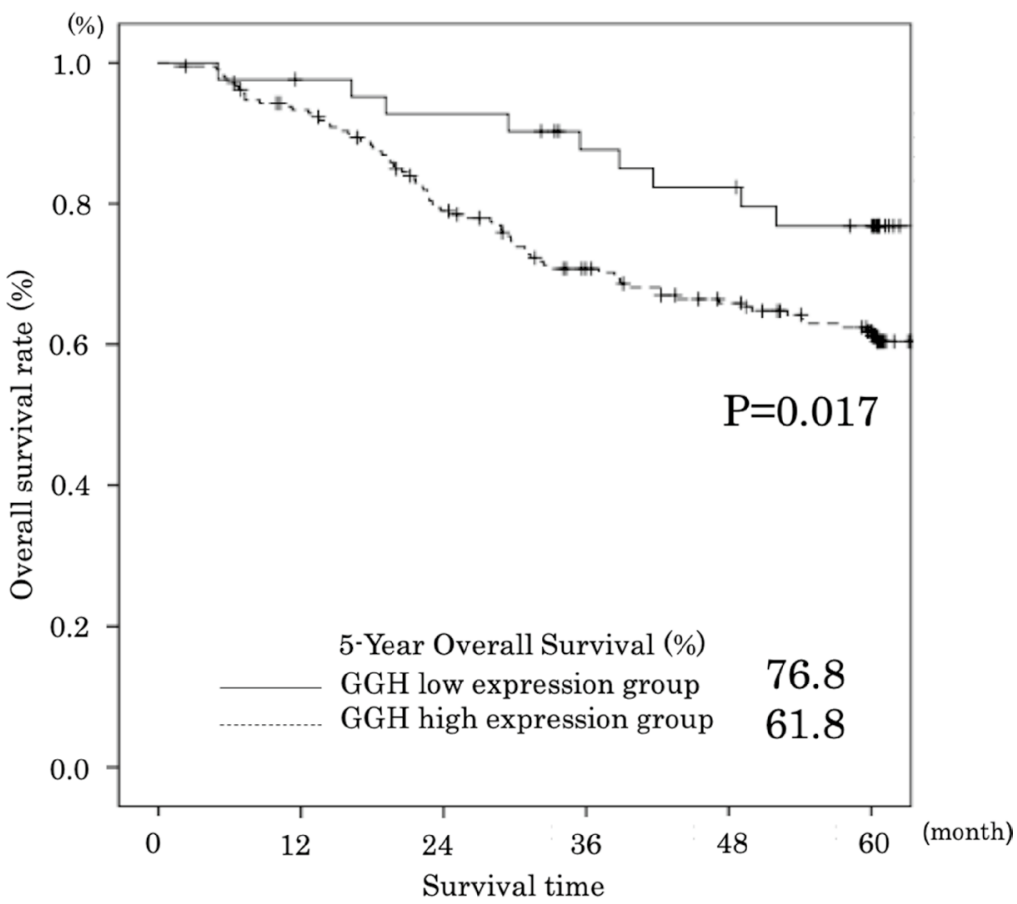

$\begin{array}{lcccccc}\text { GGH low group } & 42 & 40 & 38 & 33 & 31 & 27 \\ \text { GGH high group } & 211 & 192 & 158 & 134 & 118 & 99\end{array}$

b

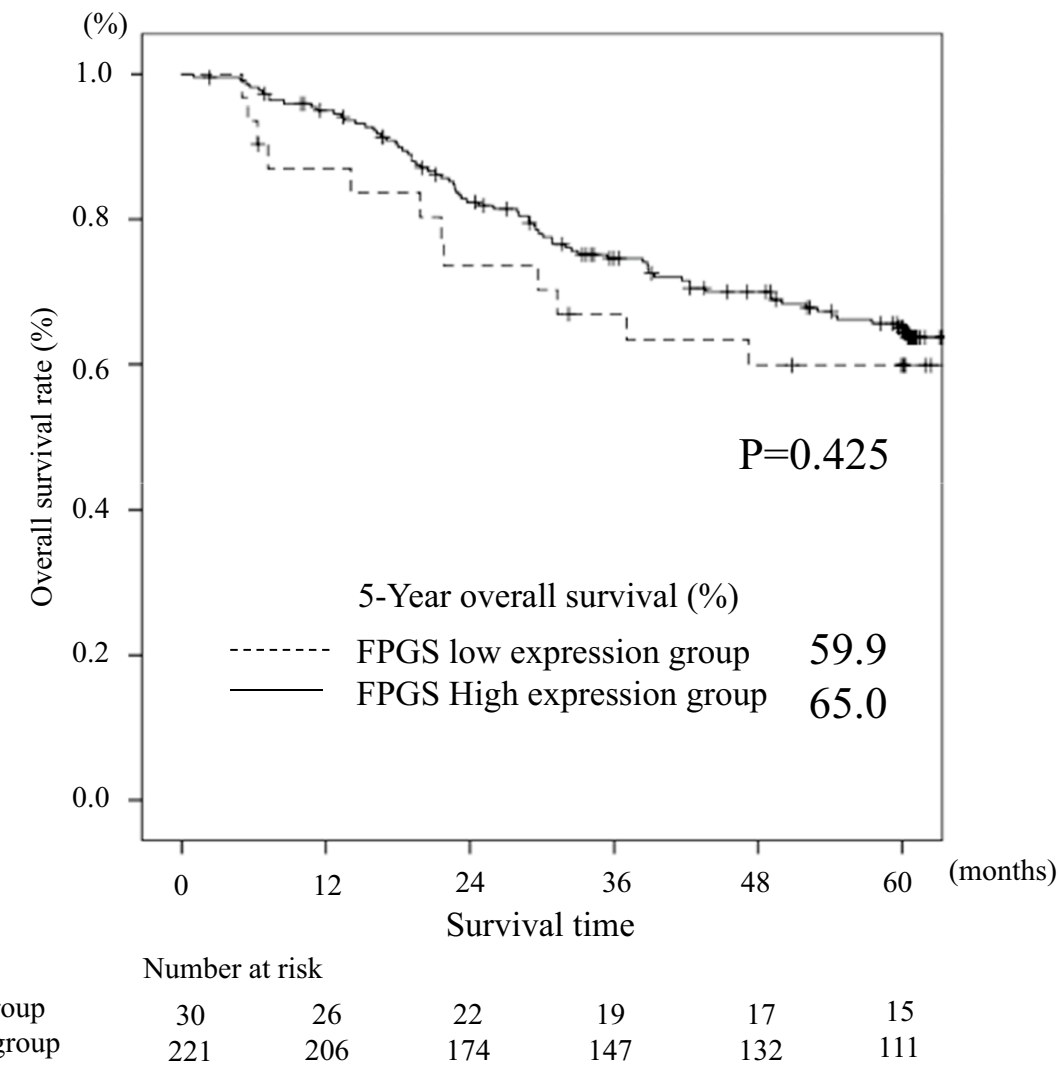

$\begin{array}{cccccc}30 & 26 & 22 & 19 & 17 & 15 \\ 221 & 206 & 174 & 147 & 132 & 111\end{array}$

FPGS low group FPGS High group 
Fig. 3 Comparison of overall survival between high and low expression levels of the GGH gene in gastric cancer tissue stratified by whether S- 1 adjuvant treatment was performed or not. a Patients who did not receive $S-1$ adjuvant treatment $(P=0.21)$. b Patients received $S-1$ adjuvant treatment $(P=0.043)$ a

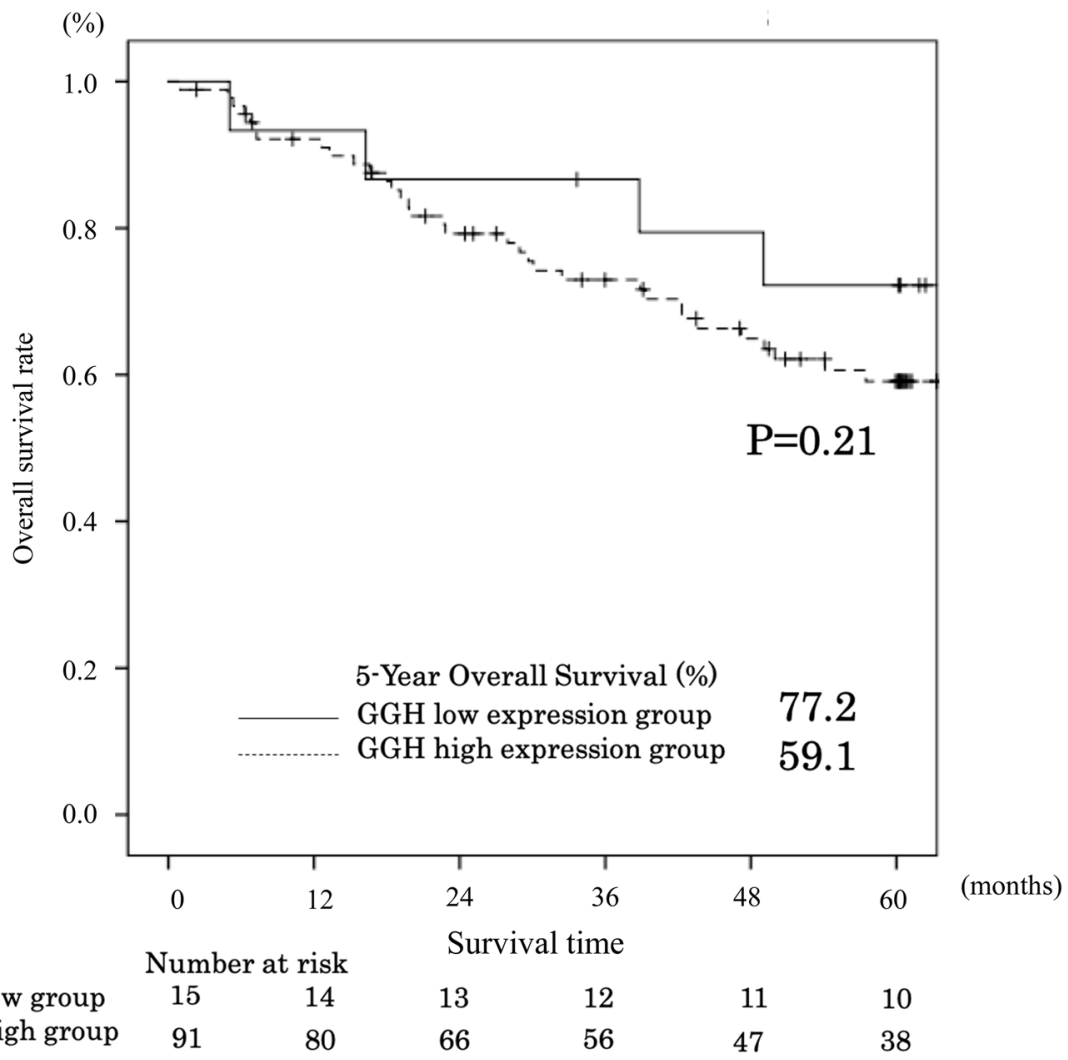

b

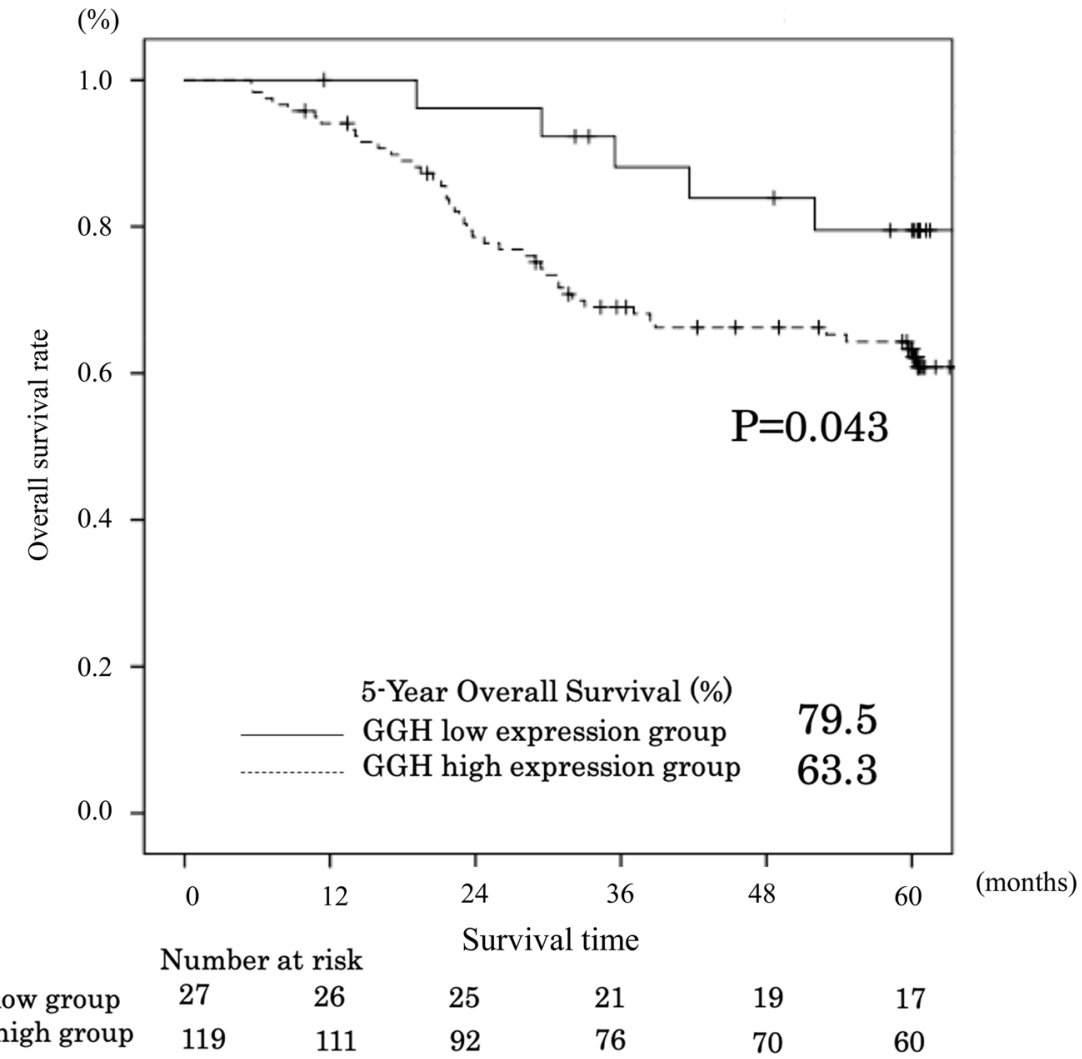


Fig. 4 Comparison of overall survival between high and low expression levels of the GGH/ FPGS gene in gastric cancer tissue $(P=0.019)$

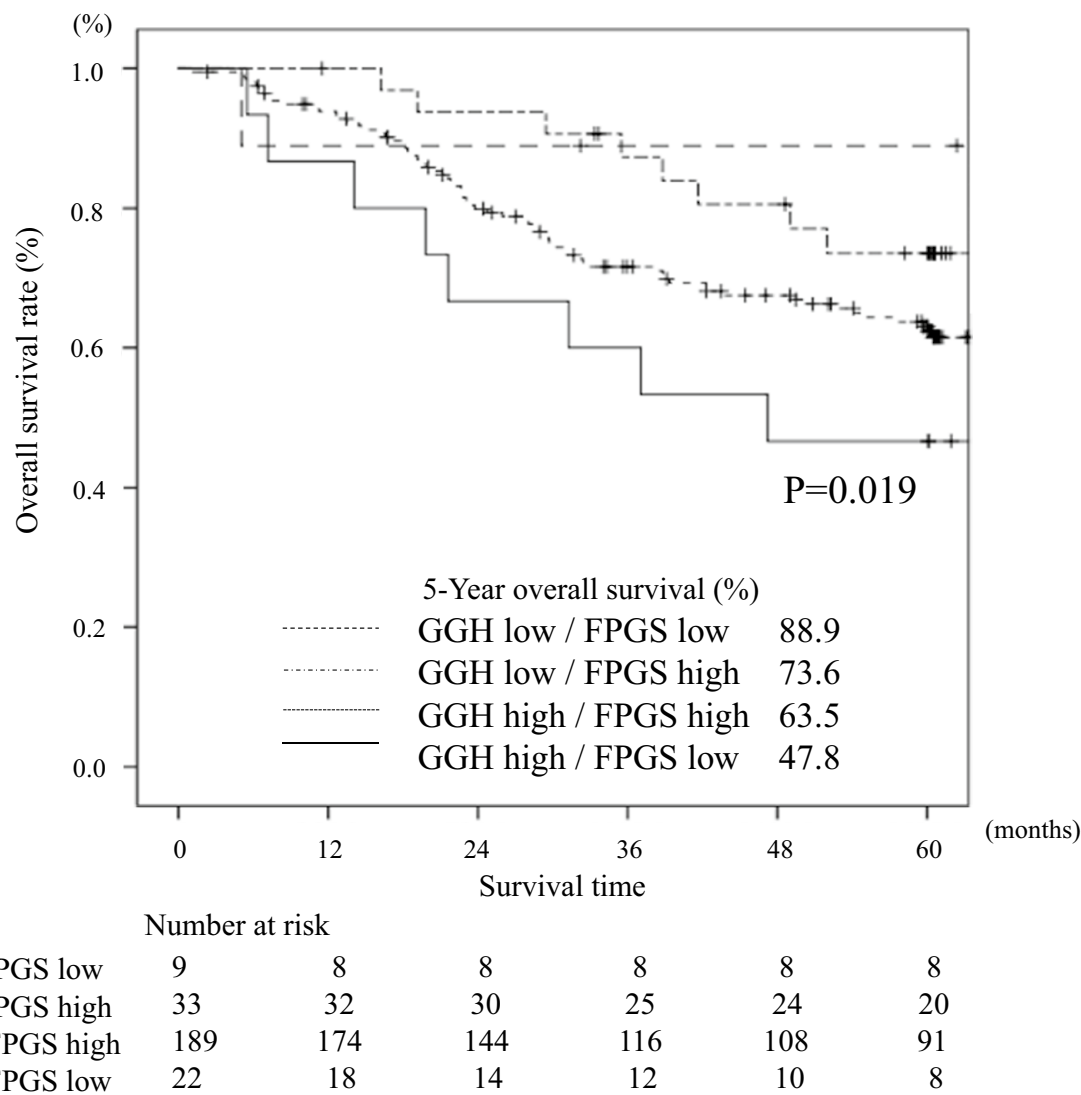

In present study, the 5-year OS was significantly poorer in patients with high levels of $G G H$ mRNA expression than in those with low expression levels. In patients with stage II/ III gastric cancer who were administrated adjuvant chemotherapy with S-1, although there was no significant difference in the 5-year OS between patients with high and low levels of FPGS mRNA expression, the 5-year OS in patients with the combination of high $G G H$ mRNA and low FPGS mRNA expression levels in cancer tissue was significantly poorer than that in the other patients.

The elucidation of the mechanism whereby high levels of $G G H$ expression and low levels of FPGS expression could be used as prognostic biomarkers in patients with locally advanced gastric cancer for which the administration of postoperative adjuvant chemotherapy with S-1 is not currently sufficient. Previous reports have suggested the following mechanism: 5-FU is an active ingredient of S-1 that inhibits the action of thymidylate synthase (TS) and suppresses DNA synthesis and cell proliferation by forming a trimer with 5-fluorodeoxyuridylate (Fd-UMP), which is a metabolite of 5-FU (Longley et al. 2003; Wilson et al. 2014). The polyglutamate folate is produced by the folate metabolism and induces the formation of the trimer (Moran 1999). GGH promotes the production of monoglutamyl acid folate, a metabolite of folic acid required for DNA synthesis. Meanwhile, FPGS catalyzes the hydrolysis of monoglutamylate folate into polyglutamate, which has a high intracellular retention (Bailey 2010). Thus, high GGH and/or low FPGS activity reduces 5,10-methylenetetrahydrofolic acid, as well as the TS, which can bind to 5,10-methylenetetrahydrofolic acid. As a result, it is possible that a small amount of 5-FU can exert a TS inhibitory effect in patients with high $G G H$ and/or low FPGS activity (Moran 1999). These mechanisms indicated that the outcomes of patients with high levels of $G G H$ expression and low levels of FPGS expression in cancer tissue were poorer than the other patients. Moreover, when combined with our results, these findings suggest that a combination of high $G G H$ expression and low FPGS expression in cancer tissue could be used as prognostic biomarkers in patients with locally advanced gastric cancer undergoing postoperative adjuvant chemotherapy with S-1 after curative resection.

This study has several limitations. First, the study examined only mRNA expression in gastric cancer tissues. Considering its clinical utility as a biomarker, future studies should examine both mRNA and protein expression levels in the same specimen. Second, there was an issue regarding the heterogeneity of the gastric cancer tissue. The sample from which the mRNA was extracted was a 5-mm square stomach cancer tissue, including the deepest part, which, however, did not completely represent the entire tumor. Third, since GGH and FPGS have contrasting effects, the 
Fig. 5 Comparison of overall survival between high and low expression levels of the GGH/ FPGS gene in gastric cancer tissue stratified by whether S-1 adjuvant treatment was performed or not. a Patients who did not receive $S-1$ adjuvant treatment $(P=0.525)$. b Patients received $\mathrm{S}-1$ adjuvant treatment $(P=0.039)$ a
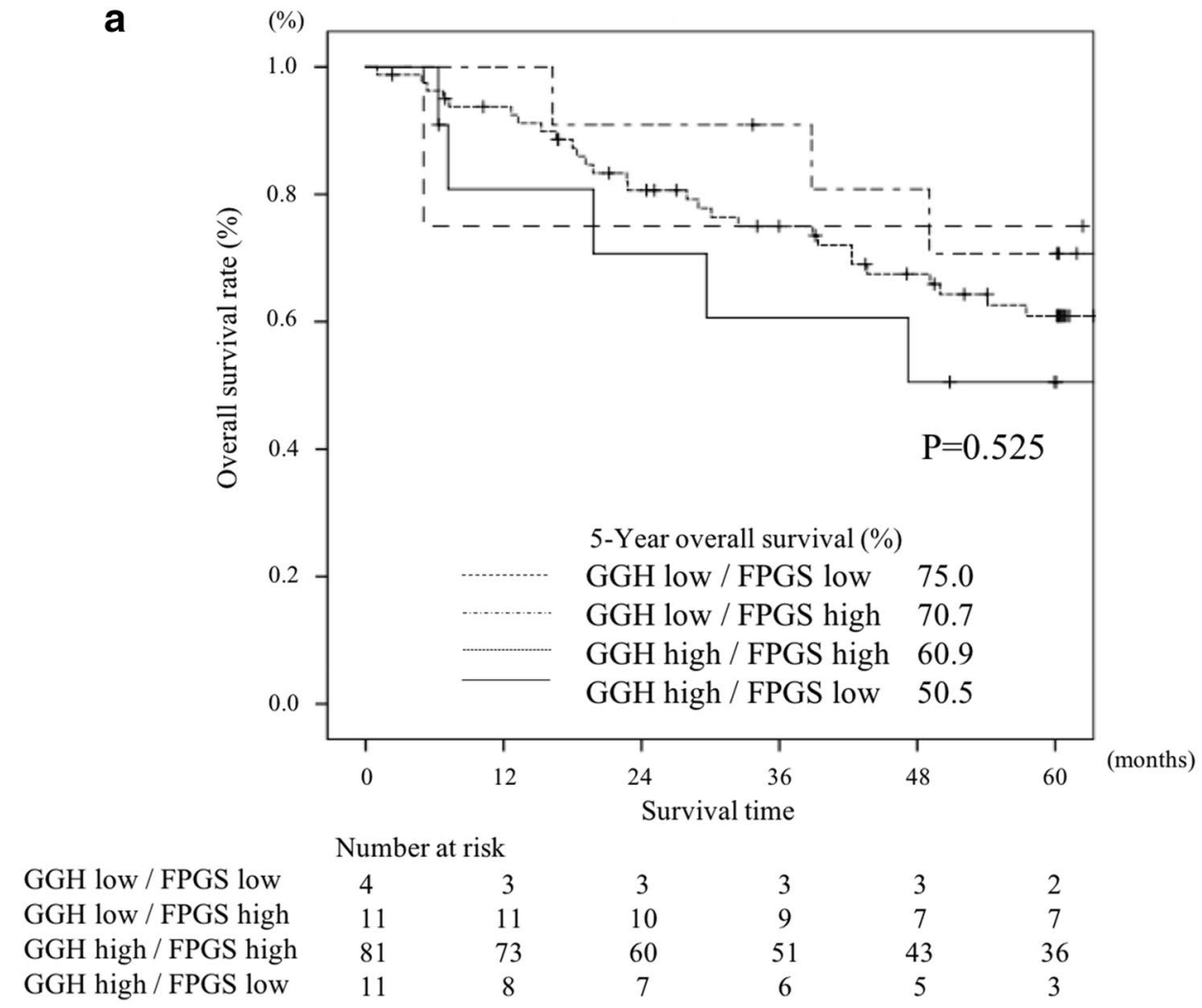

b

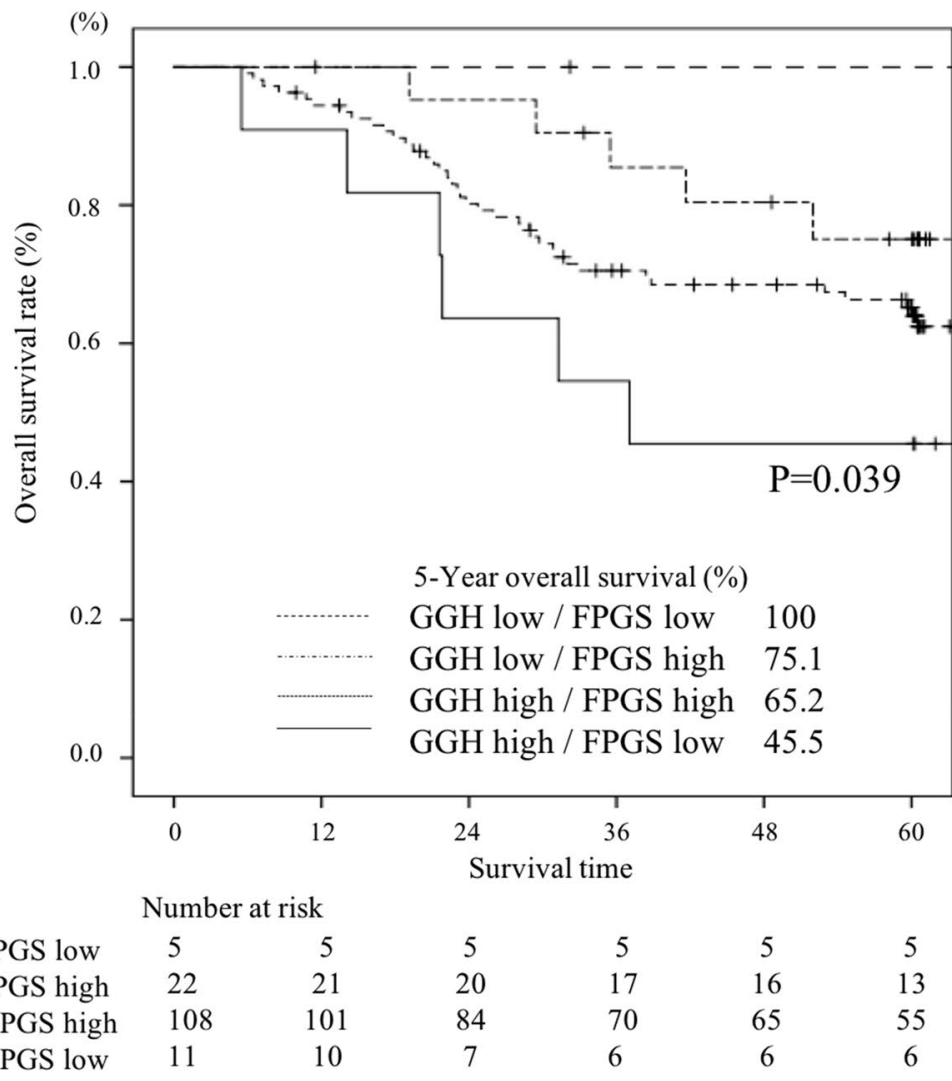


prognosis of the high $G G H /$ low $F P G S$ group could be predicted to be the worst, and, inversely, that of the low GGH/ high FPGS group the best. The present study demonstrated that a significant difference was observed when comparing the OS in the four groups based on different combinations of $G G H$ and $F P G S$ mRNA expression. In addition, there was an identically significant difference in the OS of the four groups with patients that had received $\mathrm{S}-1$ adjuvant treatment and the analysis of the two groups with high or low GGH. Although the obtained result was different from the hypothesis, which stated that the prognosis of the low $G G H /$ high FPGS group would be the best, the number of low $G G H /$ low FPGS patients was nine, which may be the cause of the lack of statistical power. As such, it is possible that the combination of $G G H / F P G S$ mRNA may have an enhanced accuracy as a biomarker.

In conclusion, high levels of $G G H$ mRNA expression and low levels of FPGS mRNA expression in cancer tissue may be useful predictive biomarkers for the survival of patients with stage II/III gastric cancer undergoing postoperative adjuvant chemotherapy with $\mathrm{S}-1$ after radical resection. It would be interesting for future studies to verify the possibility of personalizing treatments by selecting the appropriate regimen based on the expression levels of GGH and FPGS for patients with locally advanced gastric cancer in a clinical trial.

Funding No funding.

\section{Compliance with ethical approval}

Conflict of interest The authors declare that they have no competing interests.

Ethical approval This policy was in compliance with Helsinki Declaration of 1975 .

Informed consent We obtained the informed consent from all patients who entered into the present study.

Open Access This article is distributed under the terms of the Creative Commons Attribution 4.0 International License (http://creativeco mmons.org/licenses/by/4.0/), which permits unrestricted use, distribution, and reproduction in any medium, provided you give appropriate credit to the original author(s) and the source, provide a link to the Creative Commons license, and indicate if changes were made.

\section{References}

Bailey LB (2010) Folate in health and disease. CRC Press, Cambridge

Bang YJ et al (2012) Adjuvant capecitabine and oxaliplatin for gastric cancer after D2 gastrectomy (CLASSIC): a phase 3 open-label, randomised controlled trial. Lancet (London, England) 379:315-321. https://doi.org/10.1016/s0140-6736(11)61873-4

Bray F, Ferlay J, Soerjomataram I, Siegel RL, Torre LA, Jemal A (2018) Global cancer statistics 2018: GLOBOCAN estimates of incidence and mortality worldwide for 36 cancers in 185 countries. CA Cancer J Clin 68:394-424. https://doi.org/10.3322/caac.21492

Cheradame S, Etienne MC, Chazal M, Guillot T, Fischel JL, Formento P, Milano G (1997) Relevance of tumoral folylpolyglutamate synthetase and reduced folates for optimal 5-fluorouracil efficacy: experimental data. Eur J Cancer (Oxford, England: 1990) 33:950-959

Japanese Gastric Cancer Association (2017) Japanese gastric cancer treatment guidelines 2014 (ver. 4). Gastric Cancer 20:1-19. https://doi. org/10.1007/s10120-016-0622-4

Kidd EA, Yu J, Li X, Shannon WD, Watson MA, McLeod HL (2005) Variance in the expression of 5-fluorouracil pathway genes in colorectal cancer. Clin Cancer Res 11:2612-2619. https://doi. org/10.1158/1078-0432.ccr-04-1258

Kim SE et al (2013) Gamma-glutamyl hydrolase modulation and folate influence chemosensitivity of cancer cells to 5-fluorouracil and methotrexate. Br J Cancer 109:2175-2188. https://doi.org/10.1038/ bjc. 2013.579

Longley DB, Harkin DP, Johnston PG (2003) 5-fluorouracil: mechanisms of action and clinical strategies. Nat Rev Cancer 3:330-338. https:// doi.org/10.1038/nrc1074

Maehara Y, Hasuda S, Koga T, Tokunaga E, Kakeji Y, Sugimachi K (2000) Postoperative outcome and sites of recurrence in patients following curative resection of gastric cancer. Br J Surg 87:353-357. https://doi.org/10.1046/j.1365-2168.2000.01358.x

Melling N et al (2017) High-level gamma-glutamyl-hydrolase (GGH) expression is linked to poor prognosis in ERG negative prostate cancer. Int J Mol Sci. https://doi.org/10.3390/ijms18020286

Moran RG (1999) Roles of folylpoly-gamma-glutamate synthetase in therapeutics with tetrahydrofolate antimetabolites: an overview. Semin Oncol 26:24-32

Noh SH et al (2014) Adjuvant capecitabine plus oxaliplatin for gastric cancer after D2 gastrectomy (CLASSIC): 5-year follow-up of an open-label, randomised phase 3 trial. Lancet Oncol 15:1389-1396. https://doi.org/10.1016/s1470-2045(14)70473-5

Odin E et al (2003) Altered gene expression of folate enzymes in adjacent mucosa is associated with outcome of colorectal cancer patients. Clin Cancer Res 9:6012-6019

Pizzorno $\mathrm{G}$ et al (1988) Impaired polyglutamylation of methotrexate as a cause of resistance in CCRF-CEM cells after short-term, high-dose treatment with this drug. Cancer Res 48:2149-2155

Pollard C, Nitz M, Baras A, Williams P, Moskaluk C, Theodorescu D (2009) Genoproteomic mining of urothelial cancer suggests \{gamma\}-glutamyl hydrolase and diazepam-binding inhibitor as putative urinary markers of outcome after chemotherapy. Am J Pathol 175:1824-1830. https://doi.org/10.2353/ajpath.2009.090155

Rivera F, Vega-Villegas ME, Lopez-Brea MF (2007) Chemotherapy of advanced gastric cancer. Cancer Treat Rev 33:315-324. https://doi. org/10.1016/j.ctrv.2007.01.004

Sakamoto E et al (2008) Folylpolyglutamate synthase and gamma-glutamyl hydrolase regulate leucovorin-enhanced 5-fluorouracil anticancer activity. Biochem Biophys Res Commun 365:801-807. https:// doi.org/10.1016/j.bbrc.2007.11.043

Sakuramoto $S$ et al (2007) Adjuvant chemotherapy for gastric cancer with S-1, an oral fluoropyrimidine. N Engl J Med 357:1810-1820. https ://doi.org/10.1056/nejmoa072252

Shubbar E, Helou K, Kovacs A, Nemes S, Hajizadeh S, Enerback C, Einbeigi Z (2013) High levels of gamma-glutamyl hydrolase (GGH) are associated with poor prognosis and unfavorable clinical outcomes in invasive breast cancer. BMC Cancer 13:47. https://doi. org/10.1186/1471-2407-13-47

Terashima $\mathrm{M}$ et al (2017) TOP2A, GGH, and PECAM1 are associated with hematogenous, lymph node, and peritoneal recurrence in stage II/III gastric cancer patients enrolled in the ACTS-GC study. Oncotarget 8:57574-57582. https://doi.org/10.18632/oncotarget.15895

Wilson PM, Danenberg PV, Johnston PG, Lenz HJ, Ladner RD (2014) Standing the test of time: targeting thymidylate biosynthesis in 
cancer therapy. Nat Rev Clin Oncol 11:282-298. https://doi. org/10.1038/nrclinonc.2014.51

Publisher's Note Springer Nature remains neutral with regard to jurisdictional claims in published maps and institutional affiliations.

\section{Affiliations}

Yukio Maezawa ${ }^{1,5} \cdot$ Kentaro Sakamaki $^{2} \cdot$ Naohide Oue $^{3}$. Yayoi Kimura ${ }^{4} \cdot$ Itaru Hashimoto $^{1,5} \cdot$ Kentaro Hara $^{1,5}$. Kazuki Kano ${ }^{1}$. Toru Aoyama ${ }^{5}$. Yukihiko Hiroshima ${ }^{1} \cdot$ Takanobu Yamada $^{1} \cdot$ Naoto Yamamoto $^{1} \cdot$ Takashi Ogata $^{1}$. Hiroyuki Ito $^{6} \cdot$ Haruhiko Cho $^{5,7}$. Manabu Shiozawa' ${ }^{1}$ Takaki Yoshikawa ${ }^{5,8}$. Soichiro Morinaga ${ }^{1}$. Yasushi Rino ${ }^{5}$. Wataru Yasui ${ }^{3} \cdot$ Munetaka Masuda $^{5} \cdot$ Yohei Miyagi $^{9} \cdot$ Takashi Oshima $^{1}$ (1)

1 Department of Gastrointestinal Surgery, Kanagawa Cancer Center, Yokohama, Kanagawa 241-8515, Japan

2 Department of Biostatistics Informatics, Graduate School of Medicine, The University of Tokyo, Tokyo 113-8658, Japan

3 Department of Molecular Pathology, Hiroshima University Institute of Biomedical and Health Science, Hiroshima 734-8551, Japan

4 Advanced Medical Research Center, Yokohama City University, Yokohama, Kanagawa 236-0004, Japan

5 Department of Surgery, Yokohama City University, Yokohama, Kanagawa 236-0004, Japan
6 Department of Thoracic Surgery, Kanagawa Cancer Center, Yokohama, Kanagawa 241-8515, Japan

7 Department of Surgery, Tokyo Metropolitan Cancer and Infectious Disease Center Komagome Hospital, Bunkyo-ku, Tokyo 113-8677, Japan

8 Department of Gastric Surgery, National Cancer Center Hospital, Chuo-ku, Tokyo 104-0045, Japan

9 Kanagawa Cancer Center Research Institute, Yokohama, Kanagawa 241-8515, Japan 